to ultra-violet irradiation the spermatozoa exhibit a brilliant fluorescence, the acrosome appearing red or orange and the rest of the cell green. The large variations in the form of the acrosome in several species of mammals were thus clearly demonstrated. With the dye primuline a striking colour contrast is obtained between living and dead spermatozoa.

Demonstrations provided by the Division of Experimental Biology at the National Institute for Medical Research illustrated aspects of work on mammalian gametes and fertilization, reproduction in mice after ablation of the thyroid by iodine-131, gonadal geafts in the rat, production of aspermatogenesis in the guinea pig with testis antigen, and the effects on foetal development of exposure of the mother to severe hypothermia.

C. R. Austin

\section{EFFECT OF VARIOUS STIMULI ON TISSUES OF DIFFERENT AGES}

A

MEETING of the British Society for Research A on Ageing was held at the Ciba Foundation, London, on June 8, and a series of papers dealing with the effects of various stimuli on tissues of various ages was read.

The initial three papers were introduced by Prof. K. J. Franklin, under whose direction the work had been carried out. In the first paper, Dr. Sheila B. Carter, of the University of Bristol, dealt with the reaction of the gingival epithelium to friction in rats at different ages. She pointed out that, although some human experiments have been carried out in this field, work on animals may be more satisfactory since they may be kept on a standard diet under standard conditions and the amount of friction applied can be controlled. Dr. Carter used the merion rat (Meriones libycus) and three experimental groups : 5-4 months old ; 9-12 months ; and 14-16 months. In all groups the gum of the diastema between incisors and molar's of the right side of the upper jaw was rubbed with a brush consisting of a single nylon tuft about $4 \mathrm{~mm}$. long, for one minute twice daily for 4 weeks, the other side of the jaw being left as a control. The thickness of the cornified layer was afterwards measured in histological sections of the gum. The minimum width of the epithelium and the depth of the epithelial papillæ were also measured. The brushing caused a marked though variable increase (5-280 per cent) in the thickness of the cornified layer. At the same time, the minimum width of the epithelium tended to increase though not significantly; but there was a significant increase in the depth of the epithelial papillæ. It was of interest that there was no correlation between age and any histological change.

It is hoped to extend this work to a study, in the Physiology Department of St. Bartholomew's Hospital Medical College, London, of the clinical effects of mechanical friction on the human gum, and in this connexion Dr. F. J. Aumonier gave an account of his preliminary studies of the human gum. He demonstrated a striking variability in the pattern of the epithelium in human jaws which varied enormously from one side to the other in the mouth, at various levels near the teeth and in the projections of gum between the teeth. Before these clinical studies can be commenced, therefore, a very full study will have to be carried out on the variations in average thickness of gum, minimum and total thickness of the cornified epithelium, resistance to infection, etc., of the human gum in different parts of the mouth.

Dr. Patricia Lindop, of the Nuffield Gerontological Unit at the Department of Physiology, St. Bartholomew's Hospital Medical College, described three pilot experiments used in the study of the roles of whole organs in the process of ageing. The first of these dealt with the rabbit kidney, which was studied in relation to the weight of tissue and blood content at various ages. The latter was determined by using a perfusion method-washing out red cells which had been labelled in vitro with radioactive phosphorus. The renal blood content was determined within an accuracy of 2 per cent, and was found to be remarkably constant for animals of the same proportionate weight of renal tissue. In the rabbit Dr. Lindop also demonstrated that there is a distinet correlation between the weight of renal tissue and the whole body weight-that is, the smaller the animal the larger is the proportion of renal tissue. The normal renal blood content shows a parallel decrease ranging from $50 \mathrm{per}$ cent in the neonatal period to 41 per cent between weaning and puberty, and thereafter 31 per cent in adult life with no definite decrease even at three years.

The second experiment carried out by Dr. Lindop was a study of the uptake of radioiodine in 246 rats of different ages (1 day -47 weeks old). No significant difference in rate of uptake nor in the total amount of iodine taken up by the gland was recorded, although if older animals had been studied a change might have been found.

In the third series, eighty-five elderly patients between sixty-five and ninety-five years of age were studied in relation to their renal function following a period of hypotensive anæsthesia for prostatectomy. The aim of this study was to determine whether hypotension with vasodilatation, as occurs with vasomotor paralysis, is less harmful to the senile patient with reduced cardiac, cerebral and renal reserves than hypotension with vasoconstriction occurring during hæmorrhage at operation. It was found that a fall in blood pressure to a level of $80 \mathrm{~mm}$. (of mercury) systolic was optimum. There was no impairment of renal function unless the pressure was dropped below $60 \mathrm{~mm}$., when there was a transient oliguria and a rise in blood urea post-operatively.

The final paper was read by Dr. Honor B. Fell, who pointed out that early work had shown that vitamin A deficiency had caused mucous membranes to undergo a squamous metaplasia and to keratinize. Previous work by Dr. Fell and the late Sir Edward Mellanby had shown that, whereas epidermis from the trunk and limbs of 6-7-day chick embryos differentiated into squamous keratinizing epithelium in a normal medium, it formed a mucus-secreting, often ciliated, membrane when grown in medium to which excess vitamin A had been added. Dr. Fell then went on to describe experiments designed to discover whether explants of older, more highly developed, skin would undergo similar transformation in response to excess vitamin A. The scaly skin of the shank and feet of 13- to 18-day chick embryos was used.

When grown in normal medium, the 13-day skin keratinized and maintained its normal structure; but in the presence of excess vitamin $A$, it underwent mucous metaplasia as readily as the 7-day epidermis. The 18-day skin had a fairly thick stratum coineum when first explanted ; in normal medium the keratin increased in thickness, but in the high vitamin A medium it became detached by swelling and sub. 
sequent disintegration of the upper layers of epidermal cells. The deepest, least-cifferentiated cells survived, and scattered excretory cells and sometimes areas of true metaplasia appeared in this region; metaplasia was less frequent and usually less extensive than in explants of 13-day skin. When trans. ferred from high vitamin A to normal medium, both the 13- and 18-day skin eventually reverted to the squamous keratinizing type. Dr. Fell suggested that, in the organ cultures, the skin was subjected to conditions which probably could not be reproduced in the intact animal; thus experiments in vitro with excess vitamin A involved developmental potentialities which perhaps could not have been demonstrated in vivo.

G. H. Bourne

\section{PHYSICAL STRUCTURE AND ENGINEERING PROPERTIES OF CONCRETE}

$\mathrm{T}$

C. POWERS, who is in charge of fundamental research on the properties of concrete at the laboratories of the American Portland Cement Association, is well known for his work in collaboration with T. L. Brownyard on the distribution of water in set cement. Taking advantage of $\mathrm{Mr}$. Powers's attendance at the Stockholm Conference on Winter Concreting, the Cement and Concrete Association asked him to give a lecture to an invited audience in London on March 1 at the Institution of Civil Engineers. More than seven hundred persons attended, covering a wide range of interests in civil engineering and concrete technology. It is a tribute to Mr. Powers's skill and enthusiasm that the highly specialized subject-matter of his talk was nevertheless received with absorption by his large audience, who were obviously stimulated by the many original observations.

Mr. Powers began by narrowing the field of discussion to the paste of cement and water which binds together the sand and larger aggregate. In his view, the major properties of concrete are largely determined by the paste alone, and the over-riding factor controlling the quality of the paste is the ratio of water to cement in the original mix. As hydration of the cement proceeds, some of the water becomes chemically combined, some is adsorbed in the gel resulting from the hydration, and some remains as free water in the capillaries present in the set mass. The properties of the gel, as quoted by Mr. Powers, are : density, $2 \cdot 15 \mathrm{gm}$./c.c.; porosity, 26 per cent by volume; and coefficient of permeability to water, $2 \times 10^{-15} \mathrm{~cm}$. $/ \mathrm{sec}$. The last is a remarkable figure for a substance of 26 per cent porosity, being less than is obtained with natural rocks of only 2-3 per cent porosity.

Mr. Powers then went on to elaborate a theory which caused a considerable controversy. It is well known, he said, that Portland cement is composed principally of tricalcium silicate, dicalcium silicate and various aluminates. Cements high in tricalcium silicate hydrate more rapidly and gain strength more quickly than others. This is usually explained by the fact that the aluminates react quickly with water, followed by the tricalcium silicate, while the dicalcium silicate hydrates react only slowly. Nevertheless, the evidence shows that in practical cement there is no preferential hydration of the different minerals. The evidence is threefold: constant specific surface of the gel from 1 day to 14 years; constant heat of reaction per unit of combined water from 1 day to 14 years ; constant ratio of tricalcium to dicalcium silicate, as determined by the $\mathrm{X}$-ray method, from the original cement up to 28 days. Mr. Powers did not offer an alternative theory to account for the differing reactivity of cements of different mineralogical composition.

The strength of the cement paste, on Mr. Powers's theory, is determined by how much of the capillary space is filled with gel. This gel/space ratio can be calculated from the original volumes of cement and water and the degree of hydration of the cement. A good relation was shown, graphically connecting the compressive strength of neat paste and the gel/space ratio. Mr. Powers then went on to use his theory to explain the variable coefficient of thermal expansion of concrete and to consider the bulk permeability and the frost resistance of concrete; especially in dealing with the latter property, it is necessary to allow for the accidental or deliberate entrainment of air during the mixing operation.

The discussion that followed the lecture mostly centred around the question of the differential hydration of cement minerals, and it is clear that this question will exercise the minds of cement technologists for some time to come. In replying to the vote of thanks, Mr. Powers made it clear that his work is not complete and that he had offered it for discussion in the hope that any errors or weaknesses might be repaired.

R. W. NURSE

\section{MOISTURE BALANCE OF THE ATMOSPHERE}

GOR his presidential address to the Royal Meteorological Socioty, given on April 25, Dr. R. C. Sutcliffe chose for his subject "The Moisture Balance of the Atmosphere". With so much expression of opinion, both informed and uninformed, regarding the possible effects of nuclear explosions on weather and the possibility of artificially inducing precipitation from elouds, the subject was clearly a topical one; however, Dr. Sutcliffe, who is deputy-director of the Meteorological Office, had very little to say about the narrow 'rain-making' aspect and concentrated on presenting a broad picture of the various inter-related processes going on in the atmosphere, without an understanding of which attempts to tamper with the weather may lead. to confusion and, possibly, disappointment.

After lamenting the tendency for new specialist branches of meteorology and applied meteorology to channel-off research energy from the main stream, which should be concerned with atmospheric processes as a whole and which has been very much neglected, Dr. Sutcliffe made the point that the circulation of water and water vapour in the atmosphere is but one aspect of the 'general circulation' of the air which carries it. The transport of water vapour is governed by the 'macro-dynamics' - that is to say, by the equations of fluid dynamics applicable to largescale movements of air-though processes such as condensation and evaporation affect the application of mechanical principles by reason of alterations produced in the air-density. Precipitation, produced by the coalescence of cloud particles, also reacts back on 